\title{
CARACTERIZAÇÃO DA MORFODINÂMICA DE PRAIAS SOB INFLUÊNCIA DE CILINDROS GEOSSINTÉTICOS: CASO DE ESTUDO DA PRAIA DE OFIR, PORTUGAL
}

\author{
CHARACTERIZATION OF BEACH MORPHODYNAMICS UNDER THE INFLUENCE OF \\ GEOSYNTHETIC CYLINDERS: OFIRBEACH, PORTUGAL, CASE STUDY
}

\author{
Ana Carolina Gomes ${ }^{a}$, José Luis da Silva Pinhoa ${ }^{a}$ Helena Granja ${ }^{a}$ \\ aUniversidade do Minho, Portugal. \\ e-mail: carolina_gomes@live.com, jpinho@civil.uminho.pt, helenapgranja@gmail.com
}

Submissão: 10 maio de 2020 Aceitação: 18 de junho de 2020

\section{Resumo}

O fenómeno da erosão costeira afeta profundamente a costa portuguesa. O sistema praia-oceano não se pode considerar em situação de equilíbrio morfodinâmico, porque as praias são sistemas abertos, sendo os seus sedimentos constantemente transportados. Os ventos, marés e agitação marinha são os principais agentes erosivos, mas existem outras causas de origem antrópica que influenciam os processos erosivos. Este trabalho tem como objetivo avaliar as alterações morfológicas de muito curto termo em diferentes estados de agitação e tipologia de maré, na praia de Ofir, situada na costa NO Portuguesa. Esta praia foi intervencionada com cilindros geossintéticos como medida de defesa costeira. $\mathrm{O}$ trabalho é baseado num programa de monitorização, recorrendo a levantamentos topográficos de alta precisão com auxílio de equipamento DGPS. A aplicação de cilindros geossintéticos nesta praia revelou-se eficiente no período analisado e nas condições de agitação e maré verificadas, embora tenham sofrido erosão ficando expostos.

Palavras-chave: morfodinâmica costeira. levantamentos DGPS. cilindros geossintéticos.

\section{Abstract}

The phenomenon of coastal erosion deeply affects the Portuguese coast. The beach-ocean system cannot be considered in a situation of morphodynamic balance because the beaches are open systems, and their sediments are being constantly transported. Winds, tides and waves are the main erosive actions, but there are other causes of anthropogenic origin that influence erosional processes. This work aims to evaluate the morphological changes of short time scale, considering different waves and tide conditions at Ofir beach, located at the NW Portuguese coast. This beach was intervened with geosynthetic cylinders as a coastal defense measure. The work is based on a monitoring program, using high-precision topographic surveys with DGPS equipment. The application of geosynthetic cylinders on this beach proved to be efficient in the analyzed period and in the verified conditions of waves and tides, although they have suffered erosion and have been exposed.

Keywords: coastal morphodynamics. DGPS surveys. geotextile cylinders.

\section{INTRODUÇÃO}

As regiões costeiras, transição entre meios terrestre e marinho, são de importância crucial para a humanidade. De facto, é nelas que se localizam as principais cidades do mundo e, a partir delas, se acede à exploração da maior parte dos recursos marinhos (ALMEIDA, 2013). Estão, atualmente, entre as áreas com maiores densidades populacionais e a maioria das projeções indica que a migração para megacidades costeiras continuará a aumentar (NEUMANN et al., 2015; JONES; O'NEILL, 2016). A fronteira terrestre nestas regiões é, numa extensão considerável, formada por praias com 
dinâmicas complexas e cujo conhecimento detalhado apresenta enormes desafios.

As praias defendem a costa de tempestades (TEMMERMAN et al., 2013), no entanto, encontram-se em constante mudança, como resultado combinado de uma gama de fatores que potenciam erosão ou acumulação (PILKEY; COOPER, 2014; RANASINGHE, 2016), sendo as áreas mais vulneráveis as costas baixas $e$ arenosas com forte pressão humana (PEREIRA, 2004). A morfodinâmica de praias varia em função de fatores oceanográficos (SILVA, 2014), meteorológicos (MASSELINK et al., 2016) e geológicos (COOPER; GREEN; LOUREIRO, 2018). Todavia, as variações morfológicas não decorrem só de fatores naturais, existindo também uma componente antrópica (LUIJENDIJK et al., 2018; MENTASCHI et al., 2018), muitas vezes, responsável pela rápida degradação da qualidade ambiental das zonas costeiras. Em conjunto, estes fatores estarão certamente na origem do elevado défice sedimentar registado em zonas costeiras como as do NO de Portugal. Esta temática tem suscitado preocupação devido à sua severidade e ao aumento dos riscos para a população, ao longo das últimas décadas, com o recuo da linha de costa (GOMES, 2017).

As intervenções com rocha e betão têm sido uma opção para fazer face aos riscos, podendo comportar-se como soluções bastante resistentes e eficazes. Contudo, podem desconfigurar a paisagem natural costeira, acarretar custos elevados de investimento e manutenção e, em alguns casos, apesar de solucionarem 0 problema numa determinada localização, transferem-no ou agravam-no nas zonas vizinhas (GOMES, 2017). As intervenções com elementos de geotêxtil na engenharia costeira são, cada vez mais, encaradas como soluções alternativas às tradicionais, contando já com várias intervenções tanto no nível nacional como internacional; podem, em alguns casos, permitir uma defesa eficaz, duradoura e mais económica. Porém, alguma inexperiência de aplicação, ou incerteza na estabilidade deste tipo de estrutura face a agentes antropogénicos e a costas altamente energéticas, como é o caso da costa NO portuguesa, podem pôr em causa a sua utilização como alternativa a estruturas convencionais.

Com o objetivo de estudar a dinâmica duma praia intervencionada com cilindros geossintéticos, foi definido um programa de monitorização envolvendo levantamentos de perfis de praia selecionados para o efeito $e$ repetidos periodicamente, recorrendo a equipamento DGPS (Differential Global Positioning System) de alta precisão. Desta forma, foi possível avaliar as alterações morfológicas para diferentes estados de agitação e tipologia de maré, durante intervalos temporais curtos, num trecho sob influência destas estruturas de defesa costeira. Os sedimentos da praia foram caracterizados em termos dimensionais.

\section{METODOLOGIA}

A praia de Ofir situa-se na costa NO de Portugal, no concelho de Esposende, na margem sul do Rio Cávado (Figura 1), numa zona costeira densamente povoada. A agitação marinha apresenta ondas com direção predominante de oeste-noroeste, com alturas significativas de médias de $3 \mathrm{~m}$ a $4 \mathrm{~m}$ e com período médio com valores entre $8 \mathrm{~s}$ e $9 \mathrm{~s}$, nos meses de inverno (VITORINO et al., 2002).

As praias arenosas da zona costeira deste concelho, localizadas a sul da foz do rio Cávado, apresentam uma tendência erosiva, constituindo uma área de risco elevado devido à sua exposição a fenómenos climáticos extremos, como os galgamentos e inundações marítimas (LOUREIRO, 2007). Para além da diminuição das fontes aluvionares situadas na plataforma continental, admite-se que a alimentação a partir do rio Cávado tem diminuído devido à extração de areias para a construção, assim como à diminuição da capacidade de transporte do rio devido ao controlo de cheias em barragens (PORTO, 2013). Entre 2003 e 2013, o setor costeiro da praia de Ofir teve uma taxa de recuo na ordem dos 3m (GOMES, 2017).

Em 2015 foram instalados cilindros de geossintéticos preenchidos com areia, junto à base da arriba de erosão do cordão dunar, com o objetivo de 0 defender. Os cilindros foram instalados à cota $2.0 \mathrm{~m}$ (NMM) sobre uma tela de ancoragem enterrada até à cota $1.0 \mathrm{~m}$ (NMM) (Figura 1). Após a instalação, o conjunto foi recoberto com areias da praia. Este tipo de intervenção é pioneiro na costa NO Portuguesa, que apresenta uma agitação marítima muito energética, sendo o comportamento da praia e a eficiência deste tipo de intervenção 
desconhecidos.

Para avaliar o desempenho das estruturas instaladas e o comportamento da praia, definiu-se um programa de monitorização com quatro campanhas (C1 a C4), realizadas entre março e abril de 2017. Em cada campanha foram feitos quatro levantamentos durante a baixa-mar. A primeira campanha realizou-se durante um período de maré morta e as três seguintes em períodos de marés vivas, de modo a permitir efetuar os levantamentos numa maior extensão da praia. Mais recentemente, foi possível recolher amostras de sedimentos nesta praia. Recolheram-se cinco amostras ao longo de um perfil transversal de praia situado na área intervencionada e realizou-se a respetiva análise granulométrica em laboratório.

A localização dos perfis de praia ao longo da área em estudo foi definida com base em pontos de referência facilmente identificáveis no local, ao longo do período de monitorização. Foram definidos seis perfis transversais (PT1-PT6) ao longo da zona intervencionada, numa extensão de 416 metros. Para além disso, efetuou-se uma da referida extensão intervencionada, em cinco trechos, desde o limite das torres de Ofir (PT1) até ao final da zona intervencionada com cilindros geossintéticos (PT6), para facilitar a interpretação e discussão dos resultados (Figura 2).

Os levantamentos foram realizados com um equipamento DGPS Trimble Geo XR e as correções em tempo real obtidas a partir do serviço IGEOE (SANTOS, 2015). Os valores adquiridos através do DGPS foram convertidos para formato shapefile e devidamente processados para integrarem um Sistema de Informação Geográfica (SIG), criado com o software Quantum GIS (QGIS).

\section{Figura 1: Localização da praia de Ofir e características da intervenção com}
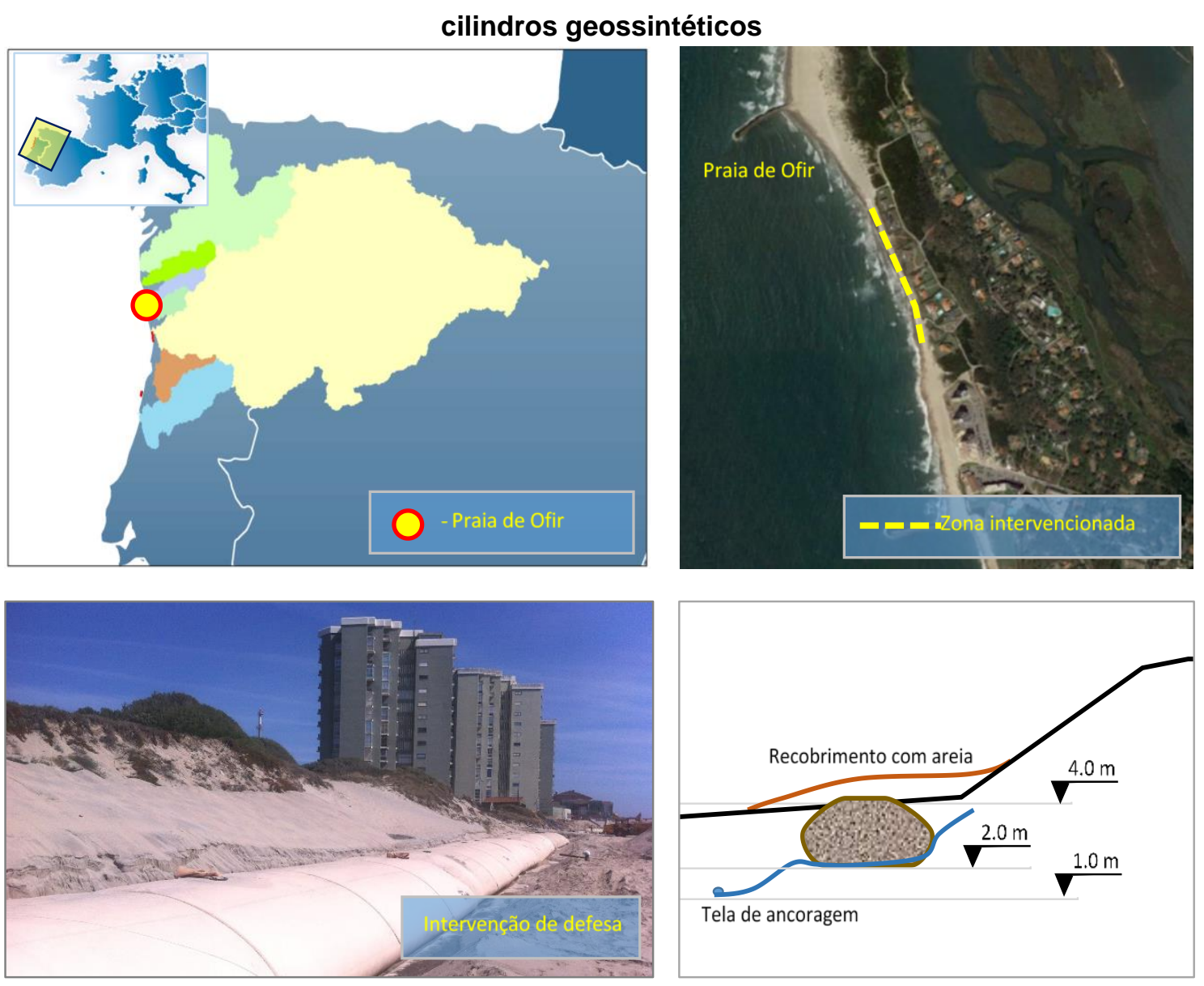

Fonte: Autores, 2020. 
A determinação da distribuição de tamanho dos sedimentos foi realizada pelo método da crivação manual sem lavagem, segundo a norma NP EN 933 (EN, 2000). Após quartejamento, NP EN 932-2 (EN, 2002), as amostras foram colocadas em tabuleiros individuais para secagem em estufa ventilada, a uma temperatura de $110 \pm 5{ }^{\circ} \mathrm{C}$. Em seguida, após arrefecimento, foram pesadas e iniciado o processo de crivação.

Figura 2: Localização dos perfis de praia e divisão em trechos

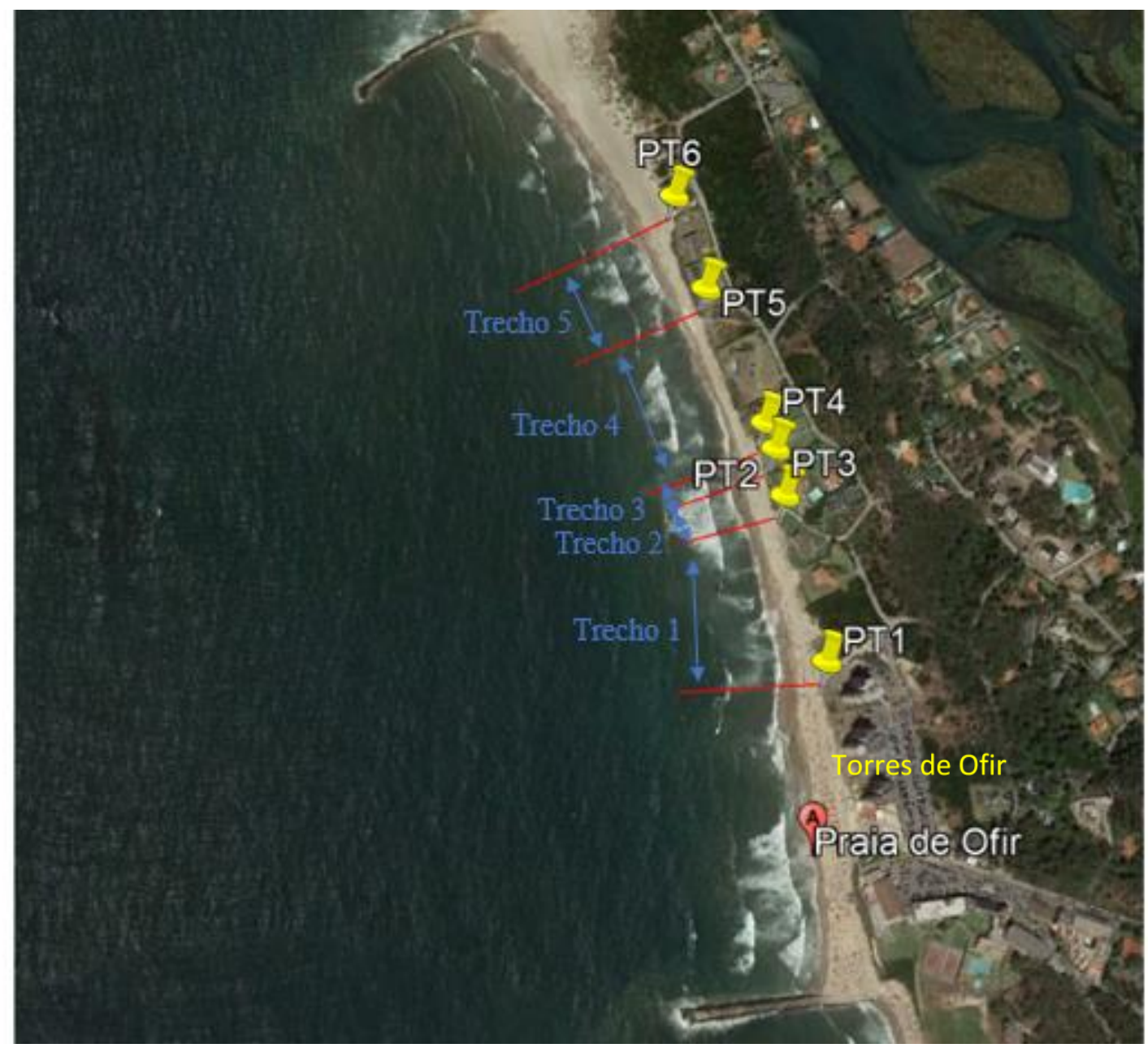

Fonte: Autores, 2020.

\section{RESULTADOS E DISCUSSÃO}

Os resultados dos levantamentos realizados nas quatro campanhas são apresentados na Figura 3. Durante o período de monitorização, a praia sofreu alterações significativas. Passa a analisar-se a situação inicial e as dinâmicas observadas entre as campanhas.

$\mathrm{Na}$ primeira campanha, realizada a 20 de março de 2017, o cenário encontrado foi de uma obra de defesa muito alterada relativamente à situação em que se encontrava após conclusão da sua instalação. A tela de ancoragem estava exposta a uma distância de $342.5 \mathrm{~m}$ (trechos 2 a 5). Esta exposição poderá estar relacionada com a forte agitação que se fez sentir no primeiro trimestre do ano (Figura 4), assim como devido a outros fatores meteorológicos, tais como vento e chuva intensa, ocorridos nesse trimestre, após conclusão da obra (não apresentados neste trabalho). No primeiro trimestre, registaram-se alturas máximas na boia ondógrafo Alfredo Ramalho (Lat $=41.14605^{\circ} \mathrm{N}$, Lon $=-9.59124^{\circ} \mathrm{W}$ ) superiores a $6.0 \mathrm{~m}$ durante cerca de 300 horas, e 
alturas significativas superiores a 10m durante 54 horas. Estas condições provocaram um rebaixamento da praia na zona dos cilindros geossintéticos, erodindo parcialmente a camada de areia de recobrimento na extensão acima indicada.

Figura 3: Perfil longitudinal da praia na proximidade dos cilindros geossintéticos e perfis transversais, nas diferentes campanhas
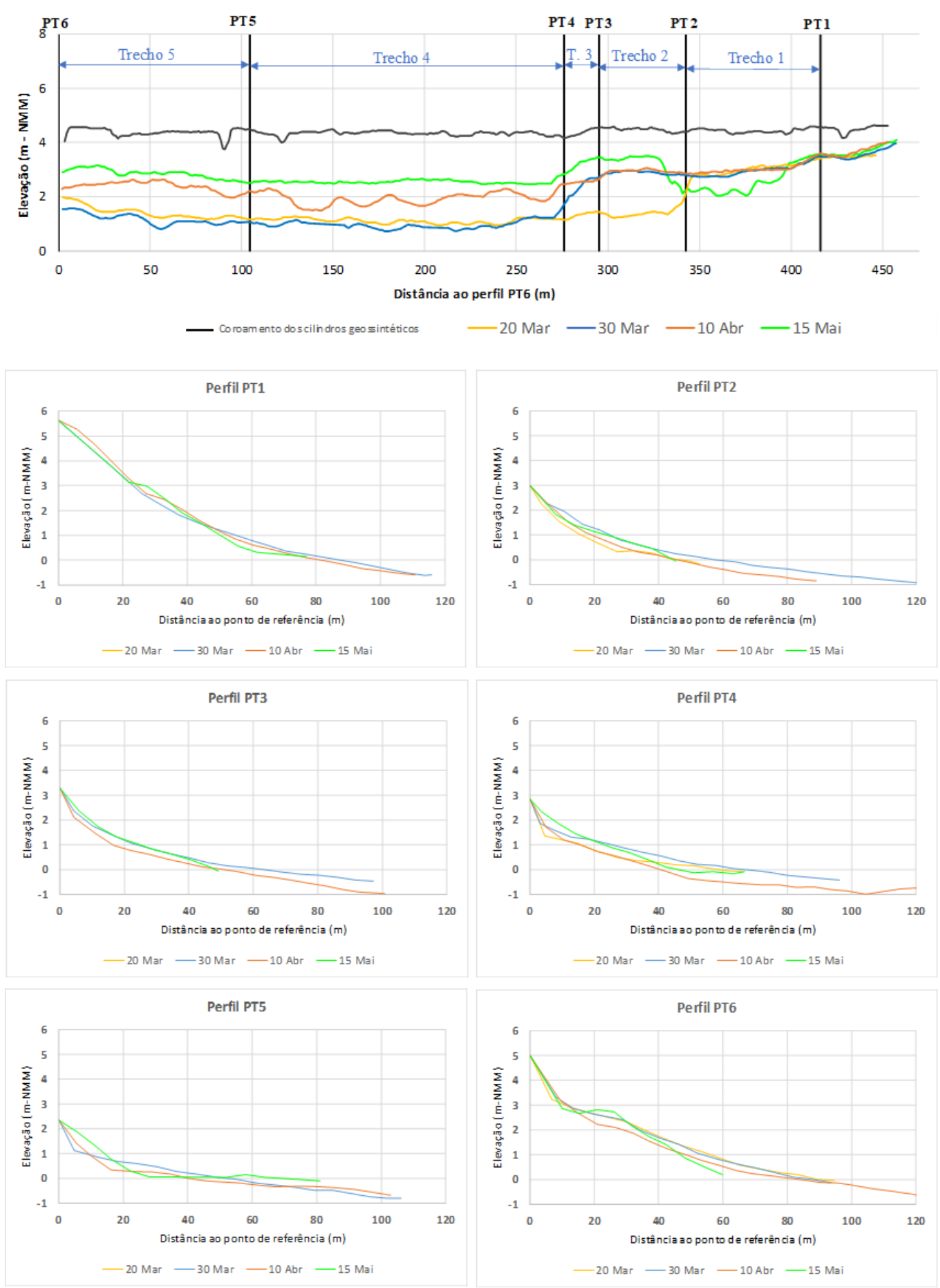

Fonte: Autores, 2020. 
$\mathrm{Na}$ segunda campanha, realizada a 30 março, a extensão de exposição da tela de ancoragem limitou-se aos trechos 4 e 5 , num desenvolvimento de cerca de $250 \mathrm{~m}$, mantendose, assim, a configuração da praia com um aspeto semelhante ao encontrado na primeira campanha. Realça-se que o nível de preia-mar nesta data $(1.70 \mathrm{~m}-\mathrm{NMM})$ foi próximo da cota de fundação dos cilindros (Figura 4).

Nos trechos 2 e 3 (delimitados pelos perfis transversais 2 , 3 e 4), ocorreu uma acreção de cerca de $0.5 \mathrm{~m}$ que permitiu o recobrimento da tela de ancoragem. Nos trechos 4 e 5, localizados mais a norte na praia em estudo, a tela de ancoragem encontrava-se completamente exposta tal como acontecia na primeira campanha realizada (Figura 5). Entre as duas campanhas ocorreram dois períodos de agitação intensa - no primeiro, a altura significativa atingiu os $6 \mathrm{~m}$ e, no segundo, os $4 \mathrm{~m}$. O período de agitação mais intensa coincidiu com a ocorrência de marés mortas (preia-mar máxima de $0.6 \mathrm{~m}$ $\mathrm{NMM}$ ) e o segundo com maré viva (preia-mar máxima de $1.6 \mathrm{~m}-\mathrm{NMM}$ ). A acreção é coerente com as condições hidrodinâmicas verificadas no período analisado, em que o transporte transversal para a praia emersa foi dominante, envolvendo ondas construtivas com swash dominante relativamente ao backwash, conforme poderá ser justificado pelos períodos médios a atingirem valores da ordem de $10 \mathrm{~s}$ nos dois períodos de agitação mais intensa.

Figura 4: Alturas da agitação registadas na boia ondógrafo Alfredo Ramalho e níveis da maré astronómica em Viana do Castelo

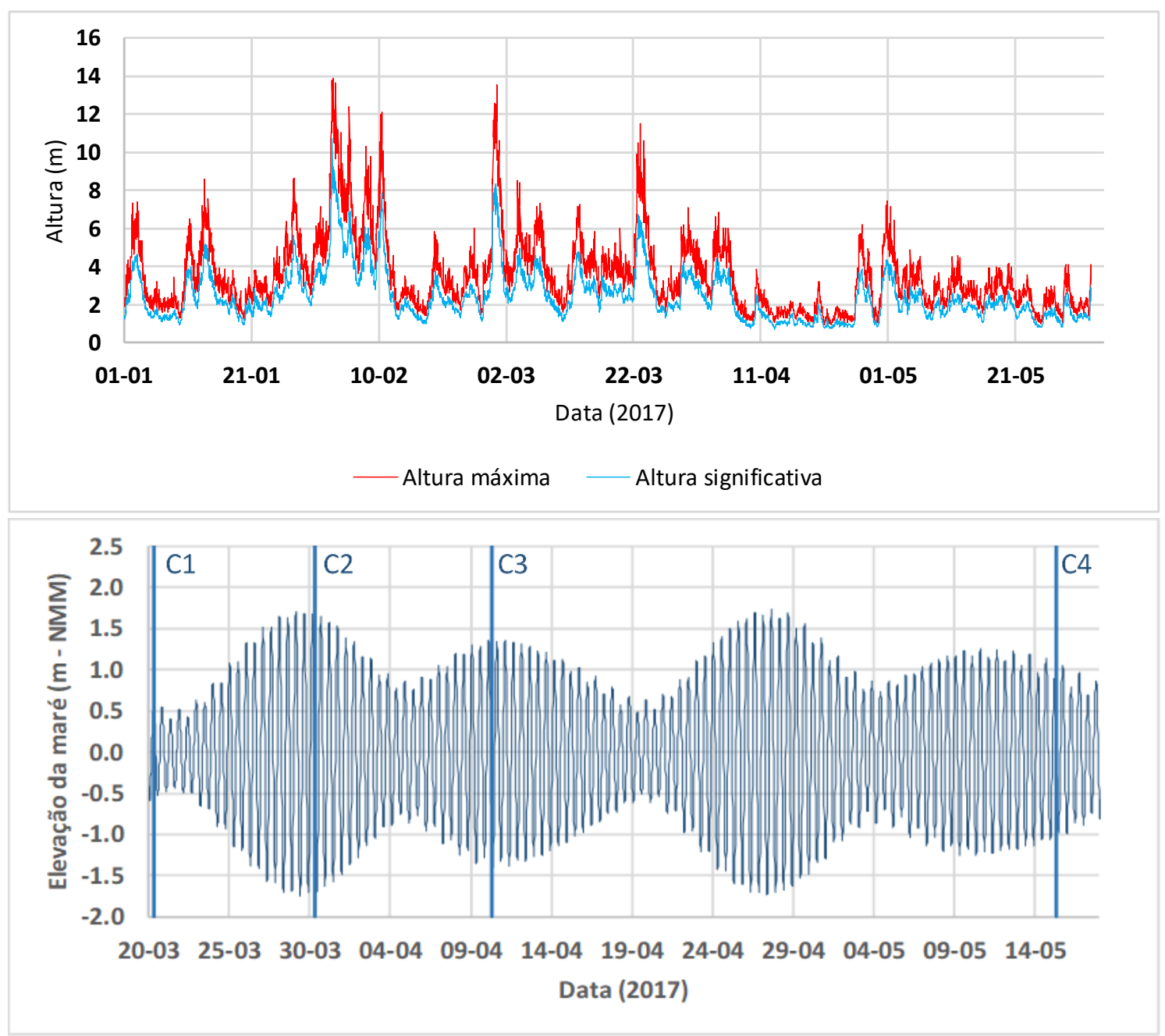

Fonte: Autores, 2020. 
Figura 3: Campanhas de monitorização (20 e 30 de março de 2017)
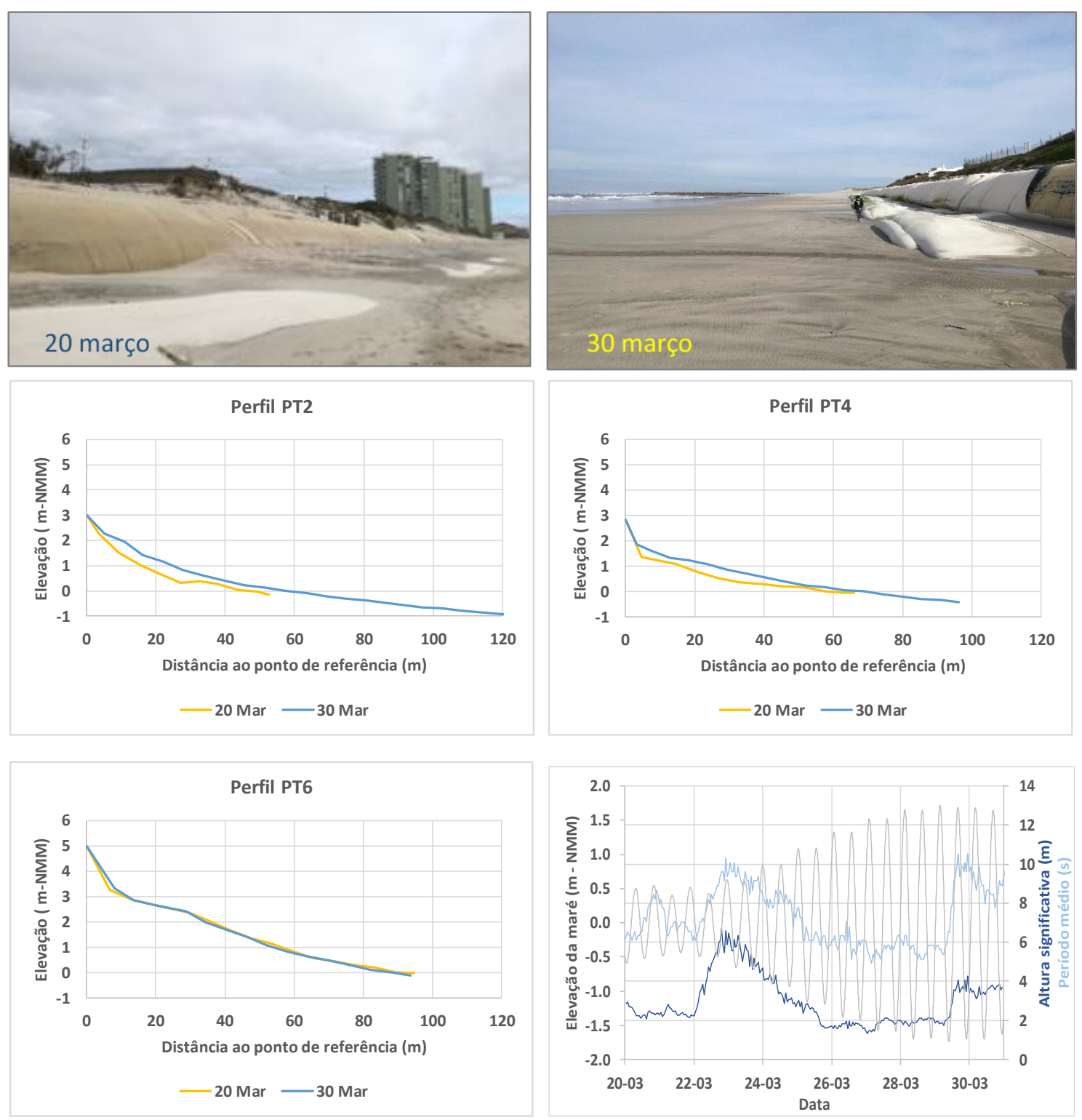

Fonte: Autores, 2020.

Entre 30 de março e 10 de abril, foi percetível uma mudança morfológica na praia. A tela de ancoragem na base dos cilindros geossintéticos, que se encontrava exposta nos trechos 4 e 5 , foi coberta por sedimentos. Contudo, a praia sofreu um rebaixamento generalizado com exceção da área junto aos cilindros de geossintéticos, nos trechos 4 e 5 . Esta acreção é visível nos perfis PT4 e PT5 (Figura 6). Tal alteração morfológica ocorreu durante um período de níveis de preia-mar maioritariamente decrescentes, com agitação menos energética do que no período analisado anteriormente. Estas condições mostraram ser propícias à acumulação de sedimentos na base da estrutura de defesa, transportados possivelmente pelo swash para níveis de maré inferiores à cota da base dos cilindros, sem ocorrência de reflexões que poderão estar na origem da erosão verificada nas campanhas anteriores. Naturalmente, que a acumulação poderá ainda ser motivada por ação eólica. 
Figura 6: Campanhas de monitorização (30 março e 10 de abril de 2017)
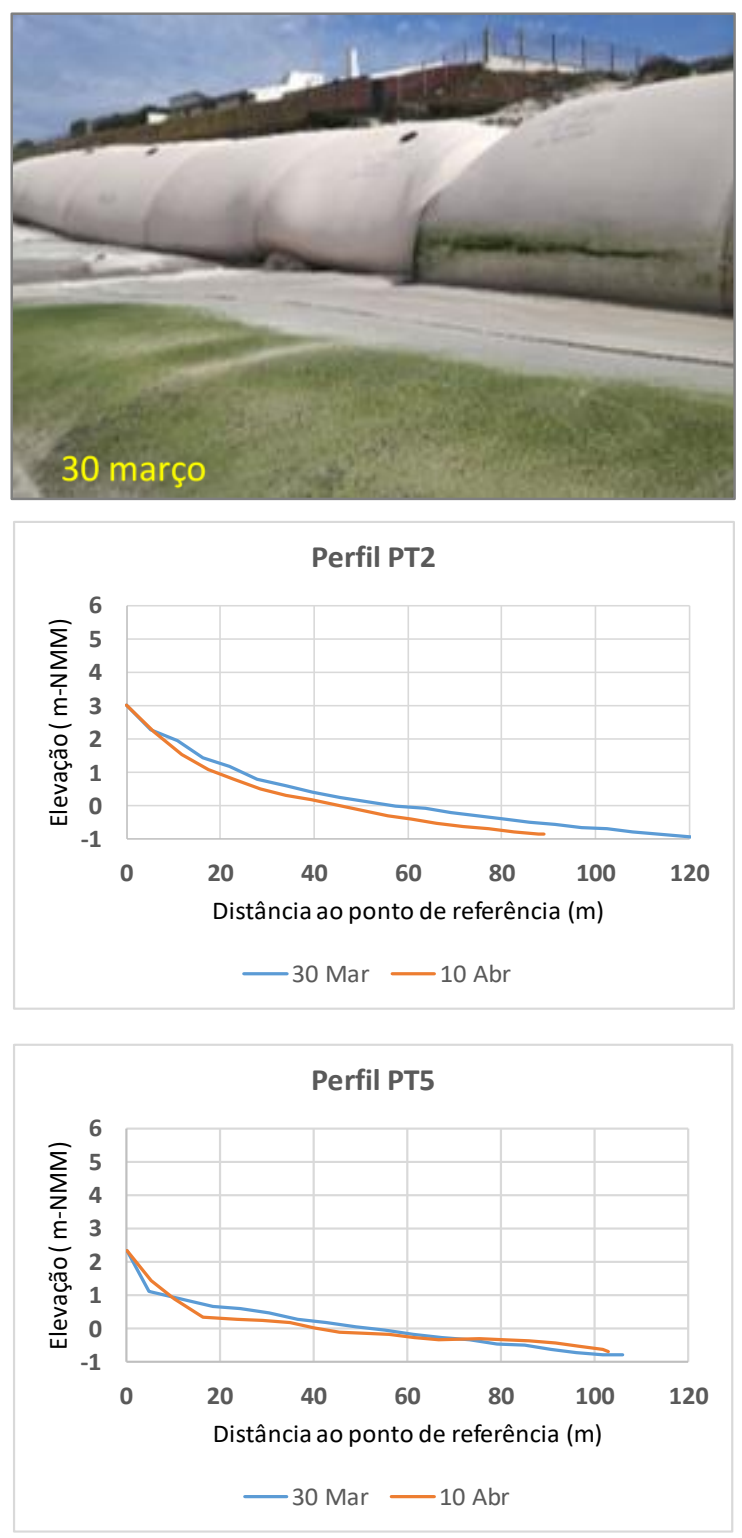

Fonte: Autores, 2020.

Na última campanha, realizada a 15 de maio, observou-se uma acreção predominante na praia, à exceção do trecho 1 que apresenta uma extensão de cerca de $65 \mathrm{~m}$ (Figura 3 ). A praia sofreu uma elevação generalizada e essa acreção é também visível no perfil PT2 (Figura 7). Entre 10 de abril e 15 de maio ocorreu um período de marés vivas em que o nível de preia mar (1.70m - NMM) foi próximo da cota de fundação dos cilindros, coincidindo com uma altura de agitação muito próxima dos $4 \mathrm{~m}$, com um período de onda de aproximadamente $7 \mathrm{~s}$. Na fase

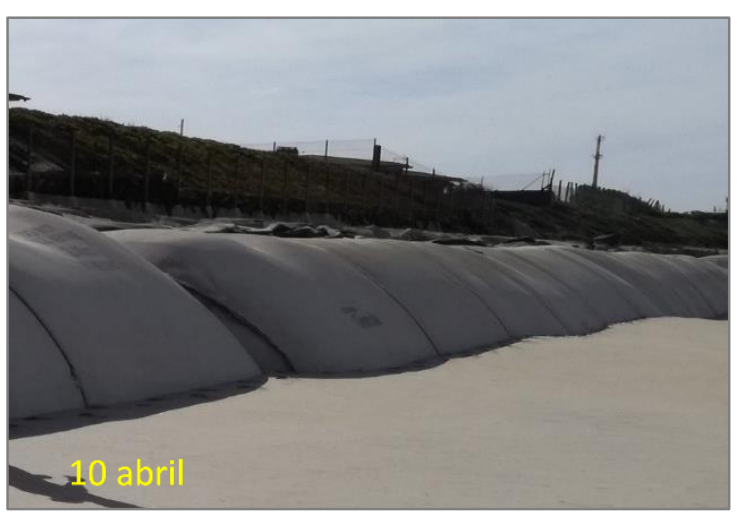

Perfil PT4
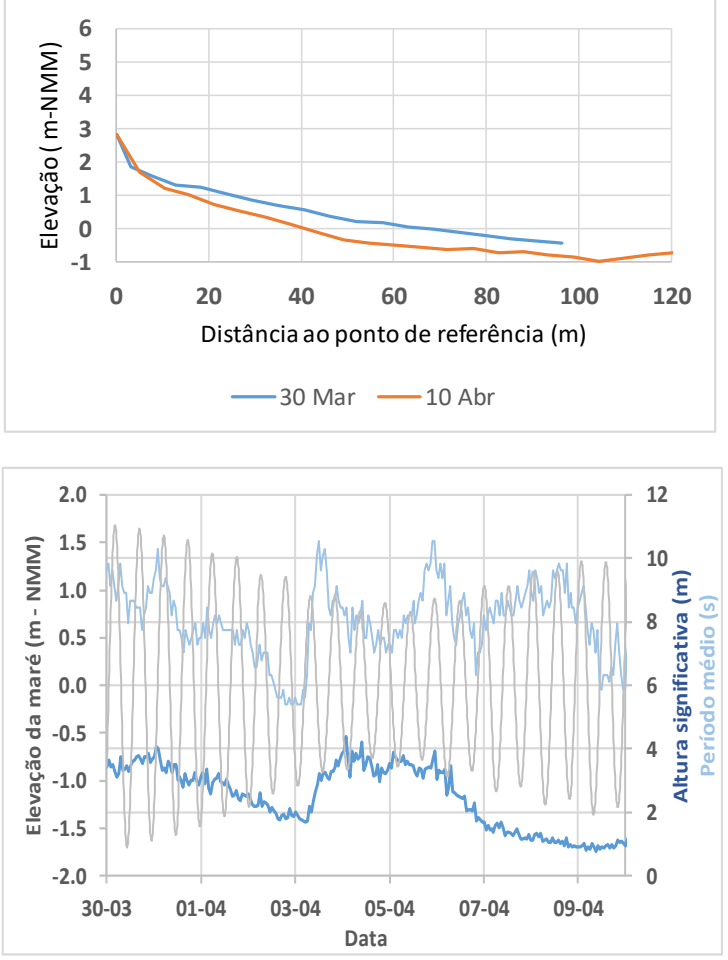

seguinte, de transição para maré morta, ocorreu um outro evento com alturas significativas da ordem dos $4.5 \mathrm{~m}$ conjugadas com períodos de 10s. É provável que estas condições tenham sido favoráveis à acreção sentida na praia, incluindo a base dos cilindros geossintéticos, sendo 0 transporte determinado pelo swash. Quanto à erosão localizada na base dos cilindros geossintéticos no trecho 1, possivelmente, deveuse ao primeiro evento mais intenso de agitação que coincidiu com marés vivas e períodos de onda de 6-7s. 
Figura 7: Campanhas de monitorização (10 abril e 15 de maio de 2017)

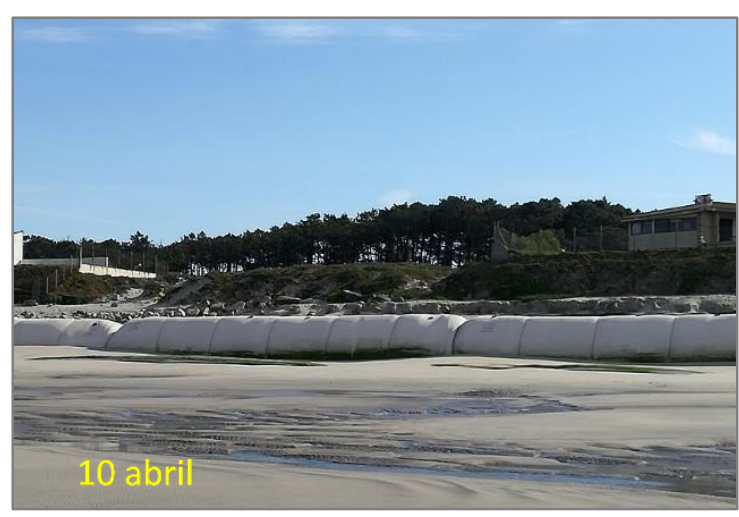

Perfil PT2
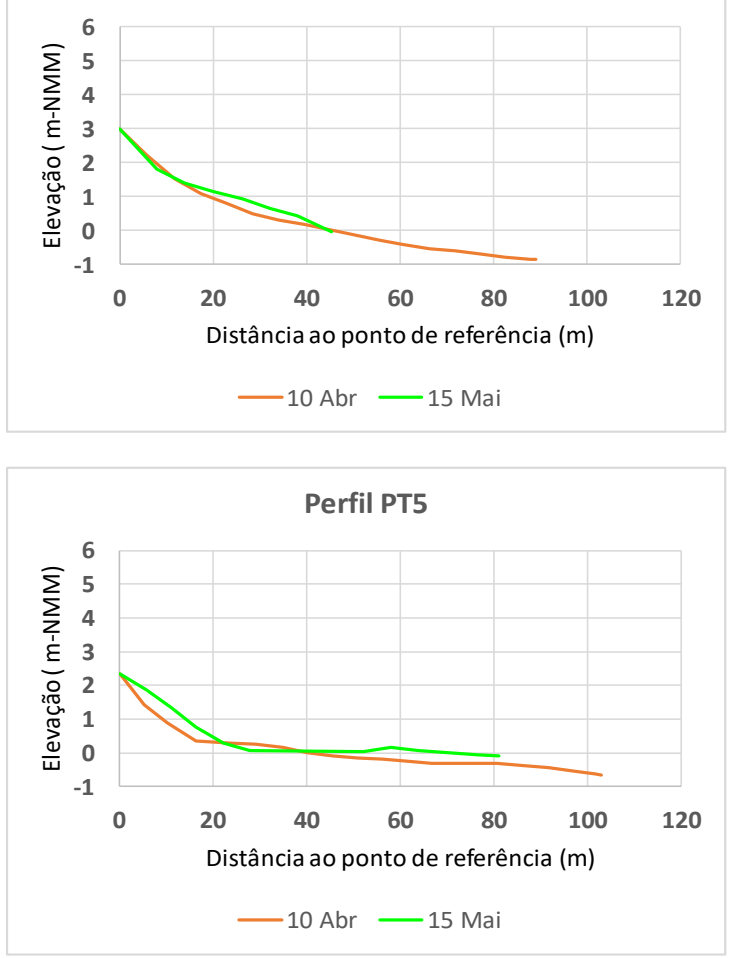

Fonte: Autores, 2020.

A evolução morfológica ao longo da área estudada não foi igual em todos os trechos, podendo distinguir-se três zonas distintas: a primeira compreendida entre PT1 e PT2 (trecho 1), a segunda, entre PT2 e PT4 (trechos 2 e 3) e a terceira, entre PT4 e PT6 (trechos 4 e 5).

No trecho 1 , as alterações na morfologia da praia ao longo do período monitorizado são pouco relevantes. As variações na base dos cilindros geossintéticos foram mínimas, exceto na última campanha. Nos trechos 2 e 3, observou-se uma acumulação sistemática de sedimentos na base dos geossintéticos, com grande expressão, principalmente, entre as campanhas 1 e 2 e

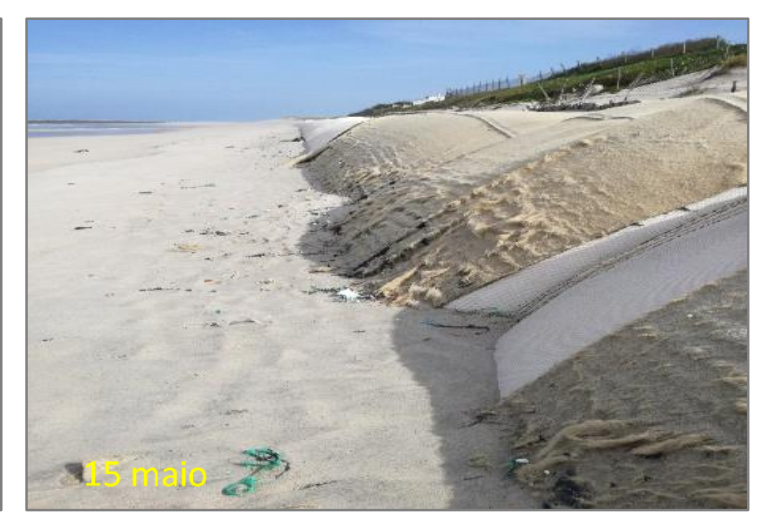

Perfil PT4

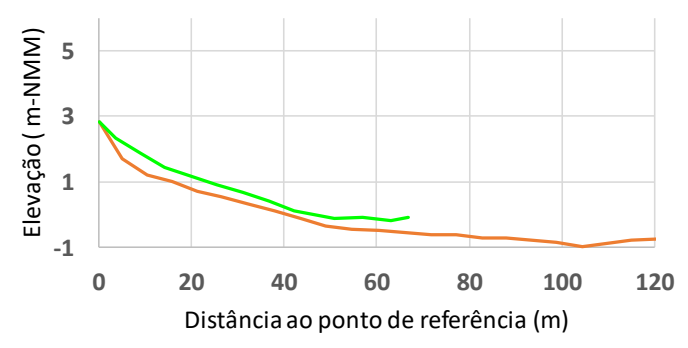

$-10 \mathrm{Abr}-15 \mathrm{Mai}$

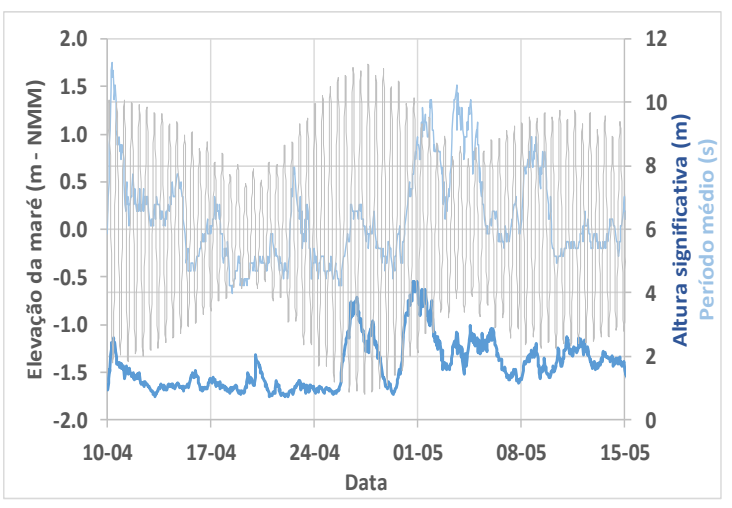

campanhas 3 e 4 . Os trechos 4 e 5 são mais expostos à ação hidrodinâmica, pois localizam-se a sotamar do esporão norte que, como é característica deste tipo de estrutura, interrompe a fluxo sedimentar associado à deriva litoral.

Os resultados das análises laboratoriais das amostras de sedimentos recolhidas na praia de Ofir mostraram que predominam areias médias (WENTWORTH, 1922), a que normalmente correspondem perfis de baixo declive (SHEPARD, 1963; MCLEAN; KIRK, 1969; DEAN 1991), conforme se apresenta na Figura 8. O diâmetro médio dos sedimentos varia entre $0.27 \mathrm{~mm}$ e $0.45 \mathrm{~mm}$, e a inclinação da face da praia 
apresenta um valor de $4.42 \%$. As inclinações dos perfis de praia junto da zona intervencionada são muito superiores.

Com a instalação dos cilindros de geossintéticos e posterior alimentação artificial, procurou-se defender o cordão dunar da ação do mar. Com a erosão posterior, verifica-se a exposição dos geossintéticos à luz solar, o que conduz a uma degradação mais rápida dos cilindros que deveria ser evitada. Assim, a alimentação artificial deveria considerar material sedimentar com as dimensões adequadas à manutenção de um perfil de praia com maior declive, conforme resultou da obra realizada.

\section{Figura 8: Inclinações da face da praia em função da dimensão dos sedimentos e valores correspondentes obtidos para a praia de Ofir}

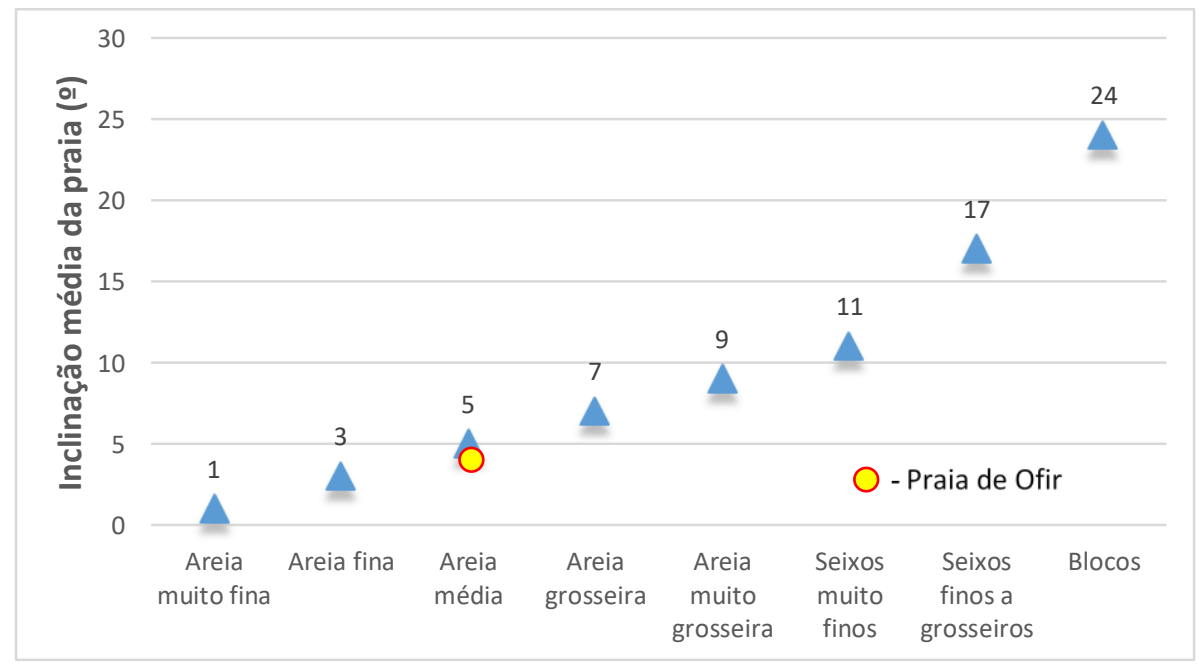

Fonte: Autores, 2020.

\section{CONCLUSÕES}

As metodologias utilizadas nos trabalhos de monitorização, complementadas com medições da maré e agitação, revelaram-se eficientes na avaliação da morfodinâmica de curto termo da praia de Ofir. A utilização de software específico para processamento de dados QGis permitiu uma análise pormenorizada da área em estudo.

Foi possível concluir que as condições de agitação e de maré são preponderantes na morfodinâmica da praia e comprovou-se que, em condições mais energéticas de agitação, as alterações sofridas são mais significativas, como se pode observar pela destruição do recobrimento da obra de defesa durante 0 inverno de 2016/2017.

Os cilindros geossintéticos têm-se mantido estáveis, embora o recobrimento sedimentar tenha sido erodido numa extensão considerável da obra. Fenómenos climáticos extremos (com vento e chuva intensa), conjugados com condições de agitação altamente energéticas, como as que se fazem sentir principalmente nos meses de inverno na costa portuguesa, obrigam à adoção de outras soluções que permitam manter os cilindros de geossintéticos cobertos com sedimentos. Embora os sedimentos finos sejam os mais confortáveis para o uso balnear, o aumento artificial da inclinação da praia pela instalação da obra de defesa deverá ser acompanhado por um dimensionamento adequado dos sedimentos do seu recobrimento, o que pressupões a utilização de sedimentos mais grosseiros. Por outro lado, deverá ter-se cuidado com a utilização de sedimentos disponíveis na praia caso sejam provenientes das dunas. Sendo estes, normalmente, sedimentos finos, implicam em praias de baixo declive; facilitando o processo erosivo por ação direta do mar sobre os cordões dunares frontais. Estes resultados põem em evidência a elevada fragilidade de importantes setores da costa portuguesa, uma vez que passam a ser alimentados quase exclusivamente 
pelas reservas sedimentares das dunas, constituídas por sedimentos de menor dimensão.

Como sugestão para trabalhos futuros, salienta-se a importância de alargar o período de monitorização, principalmente em cenários de tempestade com maiores alturas de agitação, de forma a aumentar o conhecimento sobre 0 impacto destes eventos extremos sobre os cilindros geossintéticos.

\section{AGRADECIMENTOS}

Os autores agradecem aos projetos MarRisk (0262_MarRISK_1_E) e EcOffShorBE (Eco Offshore Built Environment - NORTE-01-0247FEDER-037417), os quais apoiaram o desenvolvimento do programa de monitorização e análise granulométrica de sedimentos.

\section{REFERÊNCIAS}

ALMEIDA, J. Modelação da hidrodinâmica e da morfodinâmica do estuário do Douro. Outubro, 2013. $141 \mathrm{f}$. Tese (Mestrado em Engenharia Civil) - Escola de engenharia, Universidade do Minho, Braga, 2013.

COOPER, J. A. G.; GREEN, A. N.; LOUREIRO, C. Geological constraints on mesoscale coastal barrier behaviour. Global and Planetary Change, v. 168, p. 15-34, 2018.

DEAN, R. G. Equilibrium beach profiles: characteristics and applications. Journal of Coastal Research, v. 7, n. 1 p. $53-84,1991$.

GOMES, A. Contributos para a caraterização da morfodinâmica de praias sob influência de estruturas antrópicas. _f. Dissertação (Mestrado em Engenharia Civil) Escola de engenharia, Universidade do Minho, Braga, 2017.

Instituto Português de qualidade. NP EN 933-1. Ensaios das propriedades geométricas dos agregadosParte 1: Análise granulométrica. Método de peneiração. Caparica: Instituto Português da Qualidade, 2000.

Instituto Português de qualidade. NP EN 932-2. Ensaios das propriedades gerais dos agregados. Caparica: Instituto Português da Qualidade, 2002.

JONES, B.; O'NEILL, B. C. Spatially explicit global population scenarios consistent with the Shared Socioeconomic Pathways. Environmental Research Letters, n. 11(8), p. 1-10, 2016.

LOUREIRO, E. Indicadores geomorfológicos e sedimentológicos na avaliação da tendência evolutiva da zona costeira: aplicação ao concelho de Esposende. Julho 2007, 352 f. Tese (Doutoramento em
Geologia) - Escola de Ciências, Universidade do Minho, Braga, 2007.

LUIJENDIJK, Arjen; HAGENAARS, Gerben; RANASINGHE, Roshanka; BAART, Fedor; DONCHYTS, Gennadii; AARNINKHOF, Stefan. The state of the world's beaches. Scientific Reports, 8, n. $6641,2018$.

MASSELINK, Gerd; CASTELLE, Bruno; SCOTT, Tim; DODET, Guillaume; SUANEZ, Serge; JACKSON, Derek; FLOC'H, France. Extreme wave activity during 2013/2014 winter and morphological impacts along the Atlantic coast of Europe. Geophysical Research Letters, v. 43(5), p. 2135-2143, 2016.

MCLEAN, R. F.; KIRK, R. M. Relationships between grain size, size-sorting, and foreshore slope on mixed sand-shingle beaches. New Zealand Journal of Geology and Geophysics, v. 12(1), p. 138-15, 1969.

MENTASCHI, Lorenzo; VOUSDOUKAS, Michalis I.; PEKEL, Jean-Francois; VOUKOUVALAS, Evangelos; FEYEN, Luc. Global long-term observations of coastal erosion and accretion. Scientific Reports, 8, n. 12876, 2018.

NEUMANN, Barbara; VAFEIDIS, Athanasios T.; ZIMMERMANN, Juliane; NICHOLLS, Robert J. Future coastal population growth and exposure to sea-level rise and coastal flooding-a global assessment. PloS one, n. 10(3), p. X-X, 2015.

PEREIRA, A. R. O espaço litoral e a sua vulnerabilidade. Geoinova, Lisboa, n. 9, p. 33-43, 2004.

PILKEY H.; COOPER J. A. The last beach. Durghan, NC: Duke University, 2014. 236 p.

PORTO A. A. M. de V. Estudo Laboratorial do Comportamento de uma Restinga Móvel Confinada por Cilindros de geossintéticos. Julho 2013, $111 \mathrm{f}$. Dissertação (Mestrado em Engenharia Civil) Faculdade de Engenharia, FEUP, Universidade do Porto, Porto, 2013.

RANASINGHE, R. Assessing climate change impacts on open sandy coasts: a review. Earth-Science Reviewsv. 160, p. 320-332, 2016.

SANTOS, J. M. G. F. Avaliação da qualidade do posicionamento da rede GNSS SERVIR-CIGeoE. 2015, 140 f. Tese (Mestrado em Engenharia Geogáfica) - Faculdade de Ciências, Universidade de Lisboa, Lisboa, 2015.

SHEPARD, F. P. Submarine Geology. Tokyo: John Weatherhill, 1963. $557 \mathrm{p}$.

SILVA, A. Estudo da morfodinâmica da praia de seixos de Belinho sob a influência de diferentes estados de agitação e tipos de maré. 2014, $128 \mathrm{f}$. Dissertação (Mestrado em Engenharia Civil) - Escola de Engenharia, Universidade do Minho, Braga, 2014. 
TEMMERMAN, S. et al. Ecosystem-based coastal defence in the face of global change. Nature, v. 504 (7478), p. 79-83, 2013.

VITORINO, J. et al. Winter dynamics on the northern Portuguese shelf. Part 1: Physical processes. Progress in Oceanography, Cidade, n. 52.2-4, p. 129-153, 2002.
WENTWORTH, C. K. A scale of grade and class terms for clastic sediments. The journal of geology, v. 30, n. 5, p. 377-392, 1922. 